\title{
QUAIS AS CONSEQUENCIAS DE UM ESTRESSE INTENSO SOFRIDO PELAS CRIANÇAS ?
}

Um estresse intenso e duradouro pode desferir um golpe terrível em crianças, dizem os pesquisadores que descobriram que uma área do cérebro ligada à memória é reduzida nas crianças que sofrem estresse crônico em comparação com crianças mais que vivem em ambientes e situações que as permitem ter maior tranquilidade.

As diferenças no cérebro também permitiram iluminar algumas questões relativas à capacidade cognitiva, e mostraram como essas crianças com vidas altamente estressantes têm desempenho pior do que outras crianças em testes de memória. As crianças altamente estressadas também tiveram mais problemas com testes de memória de curto prazo, incluindo tarefas como encontrar um token em uma série de caixas, disseram os pesquisadores.

"Todas as famílias experimentam algum stress, por isso, é importante notar os efeitos que os diferentes níveis de estresse podem causar nas crianças". O pesquisador Jamie Hanson, estudante de psicologia da Universidade de Wisconsin-Madison (USA), disse à revista LiveScience, que alguns exemplos extremos podem incluir membros da família que sejam vítimas de crimes violentos ou doenças crônicas como a causa de estresse em crianças.

Uma pesquisa, detalhada na edição de 06 de junho (2011) do Journal of Neuroscience, acrescenta outra evidência dos impactos do estresse mostrando que as crianças expostas a várias instâncias de violência tem um aumento rápido do nível celular. Outro estudo mostra que o estresse infantil pode evoluir e durar anos na vida de uma pessoa.

É importante, então, que nós, familiares e profissionais que lidamos com as crianças e sua educação continuemos a tomar ciência destas informações e das análises que se produzem em torno do assunto como forma de articularmos nossas intervenções como pais, profissionais e responsáveis. 